九州大学学術情報リポジトリ

Kyushu University Institutional Repository

\title{
Thinned Wood of Cryptomeria japonica and Chamaecyparis obtusa for Production of Pholiota nameko Mushrooms in Japan
}

Cha, Joo Young

Field Science Center for Northern Biosphere, Hokkaido University

Fukui, Tomizou

Field Science Center for Northern Biosphere, Hokkaido University

Masumoto, Hiroshi

Field Science Center for Northern Biosphere, Hokkaido University

Chun, Kun Woo

Division of Forest Resource, College of Forest and Environmental Sciences, Kangwon National University

他

https://doi.org/10.5109/17793

出版情報：九州大学大学院農学研究院紀要. 55 (1)，pp.7-10，2010-02-26. Faculty of Agriculture， Kyushu University

バージョン：

権利関係: 


\title{
Thinned Wood of Cryptomeria japonica and Chamaecyparis obtusa for Production of Pholiota nameko Mushrooms in Japan
}

\author{
Joo Young CHA ${ }^{1}$, Tomizou FUKUI ${ }^{2}$, Hiroshi MATSUMOTO ${ }^{3}$, \\ Kun Woo CHUN ${ }^{4}$, Sang Yong LEE $^{4, *}$ and Shoji OHGA \\ Laboratory of Forest Resources Management, Division of Forest Ecosphere Management, \\ Department of Forest and Forest Products Science, Kyushu University, \\ Sasaguri, Fukuoka 811-2415, Japan \\ (Received September 28, 2009 and accepted November 19, 2009)
}

\begin{abstract}
We experimentally examined the artificial cultivation of Pholiota nameko, a hardwood-rotting and excellent edible mushroom, on beds of logs from thinned Cryptomeria japonica and Chamaecyparis obtusa. The water content of logs was $62.43 \%$ for Cr. japonica and $51.11 \%$ for Ch. obtusa. The sapwood, bark, and hardwood water contents were similar in the two species. Both tree species were suitable for $P$. nameko cultivation, but the numbers and fresh weight of fruiting bodies were higher on Ch. obtusa than on Cr. japonica. The number of pores drilled into logs for inoculation with fungal mycelia influences mushroom production. The number of inoculated pores per log did not affect mushroom production in Ch. obtusa, but more pores were required to produce more mushrooms in $C r$. japonica. Hence, logs of Ch. obtusa are more suitable than logs of $\mathrm{Cr}$. japonica to produce this mushroom because the fruiting bodies form on both the cross-sectional surfaces of $C h$. obtusa, as well as on the bark.
\end{abstract}

\section{INTRODUCTION}

Artificial plantations composed mainly of Cryptomeria japonica D. Don and Chamaecyparis obtusa Endl. were established in Japan after the Second World War and cover about 1000 million ha. Currently, more than half of these plantations require thinning for the conservation of forest resources and planning for development in local forestry towns (A Society for Research on Promoting Tree Thinning, 1983). However, there is little demand for the thinned wood, and labor costs are high for such operations in Japanese forests.

To promote the thinning or cleaning of conifers including $C r$. japonica and Ch. obtusa, several studies have shown that the wood removed in such operations is useful as bed logs for the cultivation of mushrooms such as Lentinula edodes (Berk.) Pegler, one of the best cultivated edible mushrooms in the world (Kido and Inagaki, 1978; Nakazawa et al., 1979; Tajima et al., 1980, 1981; Shinoda et al., 1981). However, another excellent edible mushroom, Pholiota nameko (T. Ito) S. Ito and Imai in Imai, naturally forms clumps of fruiting bodies on cut trunks or fallen logs of broadleaf trees (Imazeki and Hongo, 1995). Therefore, sawdust or bed logs from broadleaf trees such as Betula spp. and Fagus crenata are used in the artificial cultivation of this mushroom in Japan (Kinukawa and Ogawa, 2000; Oomori and Koide,

Field Science Center for Northern Biosphere, Hokkaido University, Nayoro 096-0071, Japan

Field Science Center for Northern Biosphere, Hokkaido University, Sapporo 060-0809, Japan

Field Science Center for Northern Biosphere, Hokkaido University, Wakayama 649-4563, Japan

${ }^{4}$ Division of Forest Resource, College of Forest and Environmental Sciences, Kangwon National University, Chuncheon 200-701, Korea

* Corresponding author (E-mail: sangyong@kangwon.ac.kr)
2001). However, few studies have investigated the use of bed logs from conifers for $P$. nameko cultivation (Yazawa, 1980).

While conifers such as Cr. japonica and Ch. obtuse are not suitable for $L$. edodes cultivation, there are no reports on the use of logs from $\mathrm{Cr}$. japonica or $\mathrm{Ch}$. obtusa for artificial $P$. nameko cultivation. Therefore, we examined the artificial cultivation of $P$. nameko on bed logs from these trees as a possible use for thinned logs from these tree species.

\section{MATERIALS AND METHODS}

\section{Preparation of bed logs from thinned wood}

One meter long bed logs of 24-year-old Cr. japonica and Ch. obtusa were obtained from the Wakayama Experimental Forest of Hokkaido University in Japan. To estimate the wood water content, $5 \mathrm{~cm}$ thick disks were cut from 10 bed logs of each species. The dry weights of the bark, sapwood, hardwood, and whole disks were measured after drying at $105^{\circ} \mathrm{C}$ for 1 week. The volume and surface area, excluding the cut ends, of 10 bed logs of each species were measured.

\section{Inoculation and harvesting of $\boldsymbol{P}$. nameko}

Pholiota nameko grown on sawdust was obtained from company $\mathrm{H}$ and used as the fungal inoculum. Two types of holes for inoculation were made in the bed logs using a drill: treatment $1,5 \times 10 \mathrm{~cm}$ (diameter $\times$ depth); and treatment $2,5 \times 5 \mathrm{~cm}$ (diameter $\times$ depth). After the pores were inoculated with fungal mycelia they were covered with melted wax (Figs. 3A, B). The logs were inoculated on 5 October 2000 and covered with branches of $\mathrm{Cr}$. japonica to prevent desiccation and exposure to sunlight (Fig. 3B). The number of pores inoculated with fungal mycelia was 31.6 for $\mathrm{Cr}$. japonica and 34 for $\mathrm{Ch}$. obtusa in treatment 1 and 72.4 for $C r$. japonica and 73 
for Ch. obtusa in treatment 2 on average. To induce fruiting bodies, the logs were transferred to an outdoor compound and covered by a screen to reduce light levels to 50\% (Fig. 3C). Mushrooms were collected every 2 to 3 days, and their numbers and fresh weights were determined.

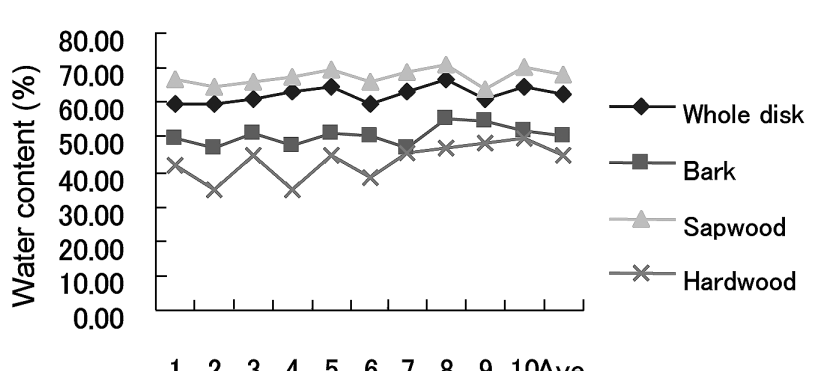

No. of samples

Fig. 1. Water content of the whole disk, bark, sapwood and hardwood in Cr. japonica bed log.
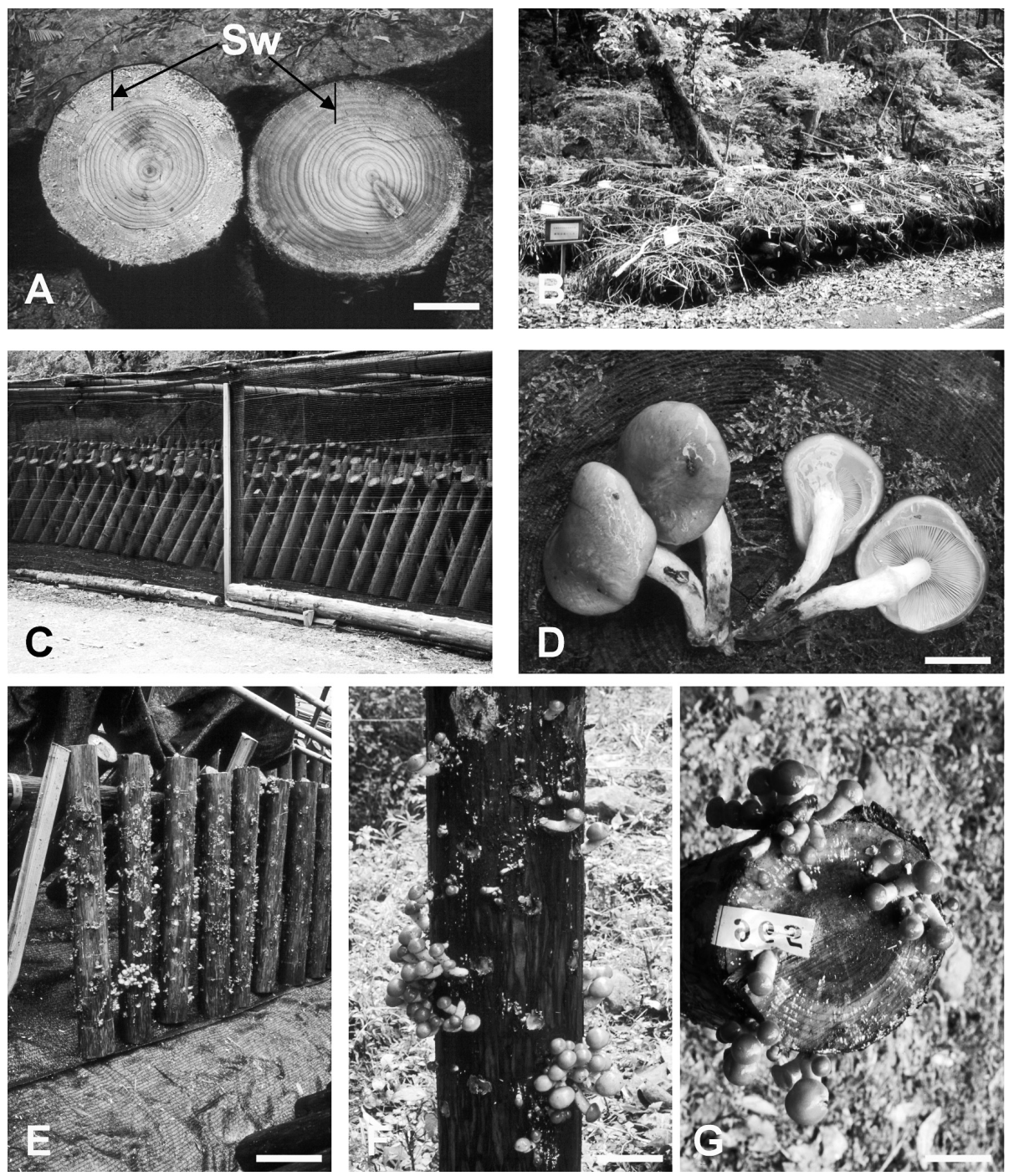

Fig. 3. Sapwood occupied by P. nameko hypha (Sw) on the bed logs of Ch. obtusa (left) and $C r$. japonica (right)(A); Bed logs covered with branches during before development mushrooms (B); Outdoor compound for developing mushrooms (C); Matured P. nameko (D); P. nameko on the surface (E, F) and on the cross-sectional surface (G) of bed logs in Ch. obtusa. Yellowish bars A, $8 \mathrm{~cm}$; D, $3 \mathrm{~cm} ; \mathrm{E}, 25 \mathrm{~cm} ; \mathrm{F}, 10 \mathrm{~cm} ; \mathrm{G}, 7 \mathrm{~cm}$.

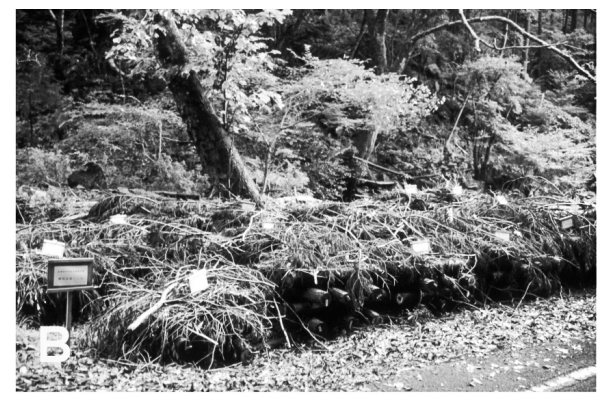

Water content of Cr. japonica and Ch. obtusa bed $\operatorname{logs}$

The average water content of the whole disks of the two tree species was $62.43 \%$ in $C r$. japonica and $51.11 \%$

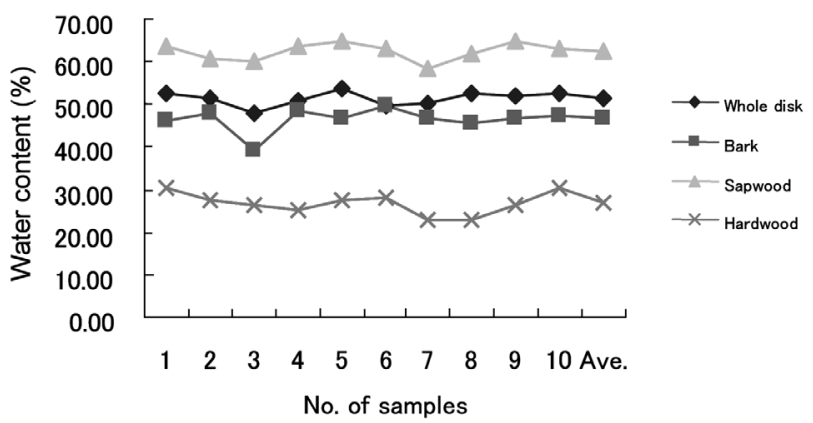

Fig. 2. Water content of the whole disk, bark, sapwood and hardwood in Ch. obtusa bed log.

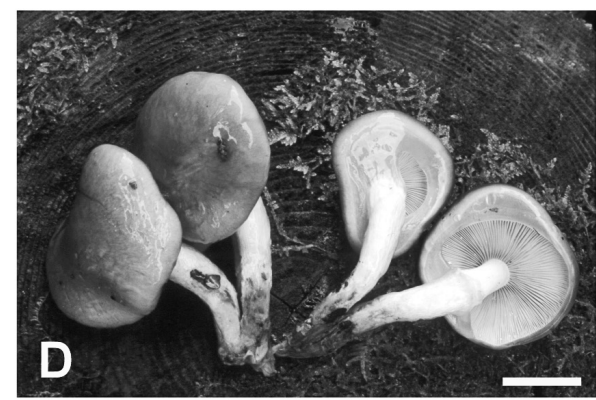

D 
in Ch. obtusa (Figs. 1 and 2). The water content of the sapwood, bark, and hardwood was similar in Cr. japonica and Ch. obtusa, and the mean water content in the hardwood of Ch. obtusa was 26.62\%. However, the water content of the whole disk affects that of the sapwood (Figs. 1 and 2).

Although $P$. nameko has strong wood-decaying ability and naturally forms fruiting bodies on both the wood and bark of stumps or fallen logs of broadleaf trees, mycelial growth is considered to differ between sapwood and hardwood in coniferous trees. In fact, the good mycelial growth on sapwood was because the bed logs have high water content (Fig. 3A), do not contain fungal-inhibiting compounds, and contain sufficient water for growth. In contrast, the hardwood, which contains antibiotic components, is not suitable for growing this mushroom (Nakamura, 1982). Hence, the ability of the mycelia to grow on hardwood is considered an important factor for mushroom production on coniferous bed logs.

\section{Mushroom harvests}

The volume of bed logs used in this experiment was approximately $0.01 \mathrm{~m}^{3}$ in each case (Tables 1 and 2), whereas the surface area, excluding the cut ends, was
$0.36 \mathrm{~m}^{2}$ (range: $0.33-0.38 \mathrm{~m}^{2}$ ) for $C r$. japonica and $0.38 \mathrm{~m}^{2}$ (range: $0.35-0.41 \mathrm{~m}^{2}$ ) for $C h$. obtusa. for $C r$. japonica, fruiting bodies of $P$. nameko appeared on all but two bed logs in treatment 1 , but the numbers and fresh weights varied widely among logs (Fig. 3E). The number of harvested mushrooms and the fresh weight of mushrooms in treatment 1 were 1.3 and 2 times, respectively, those in treatment 2 . In contrast, for Ch. obtusa, mushrooms were harvested from all bed logs, with little variation between the treatments. Moreover, mushrooms developed on Ch. obtusa over approximately 3 months, compared with 2 months for $\mathrm{Cr}$. japonica. Clearly, it is possible to use the thinned wood of $C r$. japonica and Ch. obtusa as bed logs for the cultivation of $P$. nameko.

Broadleaf tree species such as birch or beech have been used as bed logs or sawdust for the farm-scale cultivation of $P$. nameko, but cultivation using coniferous tree species such as Cr. japonica and Ch. obtusa has not previously been examined in Japan. Our results indicate that bed logs of Ch. obtusa could be suitable for the farming of this mushroom (Fig. 3F). Although the number of inoculated pores per bed log was not important for mushroom production in Ch. obtusa, more pores were required in $C r$. japonica to achieve a similar har-

Table 1. The situations on each bed log of Cr. japonica for inoculation, and P. nameko harvest

\begin{tabular}{ccccccrcc}
\hline Treatment & $\begin{array}{c}\text { No. of } \\
\text { bed log }\end{array}$ & $\begin{array}{c}\text { Volume } \\
\left(\mathrm{m}^{3}\right)\end{array}$ & $\begin{array}{c}\text { Surface } \\
\text { area }\left(\mathrm{m}^{2}\right)\end{array}$ & $\begin{array}{c}\text { Inoculated } \\
\text { pores }\end{array}$ & $\begin{array}{c}\text { Pores } \\
/ \mathrm{m}^{2}\end{array}$ & $\begin{array}{c}\text { Developed } \\
\text { number }\end{array}$ & $\begin{array}{c}\text { Raw } \\
\text { weight (g) }\end{array}$ & $\begin{array}{c}\text { Developed period } \\
\text { Mon./date/2001 }\end{array}$ \\
\hline \multirow{4}{*}{1} & 961 & 0.01 & 0.36 & 31 & 86 & 119 & 154.7 & $9 / 18-12 / 4$ \\
& 962 & 0.01 & 0.37 & 31 & 83 & 45 & 80.2 & $10 / 9-10 / 10$ \\
& 963 & 0.01 & 0.36 & 27 & 75 & 0 & 0 & - \\
& 964 & 0.01 & 0.37 & 32 & 87 & 0 & 0 & - \\
& 965 & 0.01 & 0.35 & 37 & 105 & 13 & 29.2 & $10 / 10$ \\
\hline \multirow{2}{*}{2} & 966 & 0.01 & 0.35 & 68 & 197 & 23 & 46.3 & $10 / 9-11 / 22$ \\
& 967 & 0.01 & 0.36 & 72 & 199 & 134 & 161.5 & $9 / 28-11 / 22$ \\
& 968 & 0.01 & 0.35 & 68 & 193 & 58 & 144.3 & $9 / 13-12 / 7$ \\
& 969 & 0.01 & 0.33 & 77 & 233 & 71 & 264.4 & $9 / 28-11 / 6$ \\
& 970 & 0.01 & 0.38 & 77 & 204 & 108 & 253.9 & $9 / 18-11 / 22$ \\
\hline
\end{tabular}

Table 2. The situations on each bed log of Ch. obtusa for inoculation, and $P$. nameko harvest

\begin{tabular}{ccccccccc}
\hline Treatment & $\begin{array}{c}\text { No. of } \\
\text { bed log }\end{array}$ & $\begin{array}{c}\text { Volume } \\
\left(\mathrm{m}^{3}\right)\end{array}$ & $\begin{array}{c}\text { Surface } \\
\text { area }\left(\mathrm{m}^{2}\right)\end{array}$ & $\begin{array}{c}\text { Inoculated } \\
\text { pores }\end{array}$ & $\begin{array}{c}\text { Pores } \\
/ \mathrm{m}^{2}\end{array}$ & $\begin{array}{c}\text { Developed } \\
\text { number }\end{array}$ & $\begin{array}{c}\text { Raw } \\
\text { weight (g) }\end{array}$ & $\begin{array}{c}\text { Developed period } \\
\text { Mon./date/2001 }\end{array}$ \\
\hline & 961 & 0.01 & 0.39 & 32 & 83 & 181 & 234.9 & $9 / 10-12 / 7$ \\
1 & 962 & 0.01 & 0.41 & 32 & 78 & 269 & 319.2 & $9 / 10-11 / 9$ \\
& 963 & 0.01 & 0.38 & 39 & 102 & 351 & 441.2 & $9 / 13-12 / 7$ \\
& 964 & 0.01 & 0.39 & 36 & 91 & 389 & 388.8 & $9 / 10-12 / 14$ \\
& 965 & 0.01 & 0.35 & 31 & 89 & 168 & 216.5 & $9 / 10-12 / 4$ \\
\hline & 966 & 0.01 & 0.36 & 68 & 188 & 150 & 287.2 & $9 / 12-11 / 6$ \\
& 967 & 0.01 & 0.39 & 80 & 205 & 371 & 469.1 & $9 / 10-12 / 4$ \\
& 968 & 0.01 & 0.36 & 68 & 190 & 410 & 493.9 & $9 / 10-12 / 7$ \\
& 969 & 0.01 & 0.36 & 75 & 208 & 138 & 162.7 & $9 / 10-10 / 31$ \\
& 970 & 0.01 & 0.36 & 74 & 206 & 418 & 376 & $9 / 10-12 / 7$ \\
\hline
\end{tabular}


vest.

The fruiting bodies of $P$. nameko formed not only on the bark of Ch. Obtusa, but also on the cross-sectional surfaces of the logs, which would favor the use of coniferous bed $\log _{s}$ (Fig. 3G). The ability of $P$. nameko to form on cross-sectional surfaces may be due to the thin, friable bark of conifers compared to broadleaf trees.

Although some researchers (Tajima et al., 1980, 1981) have obtained good results for $L$. edodes production on bed logs of Larix kaempferi Carr. and Ch. obtusa, other conifers such as Cr. japonica had been considered unsuitable for cultivation of this mushroom as compared with cultivation on Quercus spp. (Kido and Inagaki, 1978; Tajima et al., 1980, 1981). In particular, the quality of $L$. edodes produced from conifers was low, and in nature this species usually grows on fallen broadleaf trees (Kido and Inagaki, 1978). However, the present study produced $P$. nameko mushrooms of good shape and quality that did not differ from natural mushrooms found on fallen logs of broadleaf trees (Figs. 3D-G). The problem in using the conifer L. kaempferi as bed logs for $P$. nameko was that it was less profitable than using broadleaf trees (Yazawa, 1980). Nevertheless, further work will be needed for selection of the best strains of P. nameko for good growth on conifers such as $C r$. japonica and Ch. obtusa.

\section{CONCLUSIONS}

In Japan, $70 \%$ of the forest area on the main island is covered by $C r$. japonica and Ch. obtusa plantations. This percentage is highest in Wakayama Prefecture, in the Wakayama Experimental Forest of Hokkaido University. Forest cleaning and thinning operations entail high labor costs and produce only low-quality wood; therefore, we attempted to find a solution to this problem by identifying a use for such disposable wood. Our results indicate that this wood can be used to farm $P$. nameko mushrooms. Mushroom farming will not only provide a financial source to underwrite forest management costs, but will also aid in promoting forest preservation in Japan.

The results reported here were obtained for only 1 year after inoculations on the bed logs. Therefore, it is necessary to undertake further research to identify the length of time that $P$. nameko can be produced from each type of bed log. If production starts to decrease after 1 or 2 years due to reduced mycelial growth in the hardwood part of the logs, a new strategy may be necessary, such as using the hardwood part as material for charcoal making. Nevertheless, this study suggests an effective use for the disposable logs of $C r$. japonica and Ch. obtusa, namely for mushroom production of $P$. nameko.

\section{ACKNOWLEDGMENTS}

This study was carried out with partial support from the 2005 Specialized Priority Program for Disaster Prevention of Kangwon National University, 'Forest Science \& Technology Projects' (No. S210809L010110) provided by the Korea Forest Service. The authors would like to thank Mr. M. Teramoto, S. Kubota, S. Maeda, K. Toi, K. Oonishi, J. Maeda, S. Wada, and H. Fukuda, and Mrs. M. Teramoto, F. Konishi, and N. Teramoto of the Wakayama Experimental Forest of Hokkaido University for their cooperation.

\section{REFERENCES}

A Society for the Research of the Promoting for Thinning 1983 Collection of examples for effective using of thinned woodform the thinning operation to the processing and distribution of thinned wood. Chkyusya, Tokyo, Japan. p. 303 (In Japanese)

Imazeki, R. and T. Hongo 1995 Colored illustrations of mushrooms of Japan Vol. I. Hoikusya Publishing Co., LTD. Osaka. Japan. p. 325 (In Japanese)

Kido, S. and K. Inagaki 1978 The $4^{\text {th }}$ report on the technique for the cultivation of Lentinula edodes on the bed logs of Chamaecyparis obtusa. Report on operations of Forestry Center in Wakayama Province, no 44: 72-74 (In Japanese)

Kinukawa, K. and M. Ogawa 2000 A handbook of mushroom. Asakurasyouten Co., Tokyo. Japan. p. 448 (In Japanese)

Nakamura, K. and M. Iioka 1951 Studies on the culture-woods of Siitake. Rearing and Collection, 13: 102-104

Nakamura, K. 1982 Dictionary of mushroom. Asakura Co., Tokyo, Japan p. 492

Nakazawa, K., R. Akiyama, A. Kato, M. Sato and K. Hikawa 1979 Artificial fruiting of Lentinus edodes using felled logs of Larix leptolepis. Trans. Mycol. Soc. Japan, 20: 499-503

Oomori, S. and H. Koide 2001 Whole curriculum for mushroom cultivations. Noubunkyou, Tokyo, Japan. p. 258 (In Japanese)

Shinoda, Y., M. Kawase, M. Inaba and T. Tajima 1981 Wood components in the bed logs of Lentinula edodes. Transaction of the Japanese Wood Science Society, No. 31: 213 (In Japanese)

Tajima, T., M. Kawase, Y. Shinoda and M. Inaba 1981 Thinned wood of conifer using for the bed log for Lentinula edodes cultivation (III). Transaction of the Japanese Wood Science Society, No. 31: 214 (In Japanese)

Tajima, T., Y. Shinoda and H. Tsuge 1980 Thinned wood of conifer using for the bed log for Lentinula edodes cultivation (II). Transaction of the Japanese Wood Science Society, No. 30: 202 (In Japanese)

Yazawa, K. 1980 Cultivation of Pholiota nameko using thinned woods of Larix kaempferi; Problem is profitability. A new knowledge of forestry, no. 315: 10-13 (In Japanese) 